\title{
INFLUÊNCIA DA COBERTURA DE INVERNO NOS ATRIBUTOS FÍSICOS DO SOLO EM CULTURAS DE MILHO E SOJA SOB PLANTIO DIRETO
}

\author{
Elisandro Paulo Pickler ${ }^{1}$, Lúcia Helena Pereira Nóbrega ${ }^{2}$, Gislaine Piccolo de Lima ${ }^{3}$, \\ Marcia Regina Siqueira Konopatzki ${ }^{4}$, Fabio Palczewski Pacheco ${ }^{4}$
}

\begin{abstract}
RESUMO
A intensa mecanização, aliada ao manejo inadequado, contribui para alterações na estrutura do solo, facilitando os processos erosivos e a constante degradação ambiental. As plantas de cobertura auxiliam no processo de proteção superficial, na melhoria de atributos físicos, químicos, biológicos e potencial produtivo do solo, minimizando a degradação. Assim, este trabalho teve como objetivo analisar a variação da densidade, teor de água, macro e microporosidade do solo sob cobertura vegetal de inverno, durante o cultivo de soja e milho, em sistema plantio direto. O experimento foi em campo, com 24 parcelas, seis tratamentos de cobertura vegetal: nabo forrageiro, milheto, colza, aveia preta, trigo e pousio, com quatro repetições. Após o manejo da cobertura vegetal, foram semeadas doze parcelas com milho e doze com soja. Observou-se que o solo cultivado com milho apresentou melhores resultados para macroporosidade, porosidade e densidade, quando comparado ao solo cultivado com soja. A cobertura vegetal de nabo forrageiro aumentou a macroporosidade do solo. As plantas de cobertura não influenciaram os valores de teor de água, densidade, microporosidade e porosidade.
\end{abstract}

Palavras-chave: Macroporosidade, microporosidade, rotação de culturas

\section{ABSTRACT \\ INFLUENCE OF WINTER COVER CROP ON THE PHYSICAL ATTRIBUTES OF SOIL IN NO- TILLAGE FRAMS CULTIVATED TO SOYBEAN AND CORN}

The increased mechanization, without adequate management, contributes to changes in soil structure, which facilitate erosive processes and soil degradation. The cover crops help protect soil surface, enhance physical, chemical, biological and productive potential of a soil and minimize degradation. This trial was done to analyze the influence of winter cover crop on the soil density, water content, macro and microporosity of soil cultivated to soybean and corn under no-tillage system. The experiment was conducted in a field with 24 plots, having six treatments of cover crops (forage turnip, pearl millet, oilseed rape, black oat, wheat and fallow) with four replications. After cover crop management, twelve plots were planted with corn and the other twelve with soybeans. It was observed that the soil under corn had better macroporosity, porosity and density compared to the soil cultivated to soybean. The crop cover with forage turnip increased soil macroporosity. However, cover crops did not influence water content, density, microporosity and porosity.

Keywords: Macroporosity, microporosity, crop rotation

\section{Recebido para publicação em 01/01/2010. Aprovado em 20/10/2011.}

1- Eng. Agrícola - BUNGE, email: elisandropickler@hotmail.com

2- Eng. Agrônoma, Profa. Associada, Programa de Pós Graduação em Engenharia Agrícola - PGEAGRI, CCET - Unioeste Campus de Cascavel - PR. e-mail: lucia.nobrega@unioeste.br

3- Bióloga, Aluna e-mail: gisalipi@yahoo.com.br

4- Eng. Agrícola, Alunos do Programa de Pós Graduação em Engenharia Agrícola, CCET - Unioeste - Campus de Cascavel - PR, marciak@pop.com.br, fabiohuck2001@yahoo.com.br 


\section{INTRODUÇ̃̃O}

Um dos sistemas de cultivo predominantes na Região Sul do Brasil é o plantio direto, no qual, os resíduos da cultura ficam na superfície do solo, formando o que se designa por cobertura morta. As culturas utilizadas como cobertura de solo têm, em geral, a capacidade de reciclar nutrientes, promover a descompactação do solo, aumentar o teor de matéria orgânica e suprimir as plantas invasoras (VIDAL ; TREZZI, 2004; THEISEN et al., 2000).

O plantio direto, associado à prática de rotação de culturas, é o sistema agrícola mais próximo da sustentabilidade, com menor impacto ambiental. A rotação de culturas, realizada de forma correta inclui a utilização de adubação verde (ROSA et al., 2009), realizada por meio das plantas de cobertura.

O uso de plantas de cobertura corresponde à utilização de plantas em rotação, sucessão ou consorciadas em cultivos, com a finalidade de proteção superficial, assim como a manutenção e melhoria das propriedades físicas, químicas e biológicas do solo, inclusive as profundidades significativas, graças aos efeitos de suas raízes, as quais promovem melhor equilíbrio e maior produção de biomassa, com consequente aumento do potencial produtivo do solo (CALEGARI, 2006).

É perceptível a diminuição da infestação de plantas invasoras com o uso de plantas de cobertura, principalmente no uso do consórcio de plantas, por este apresentar maior produção de biomassa, a qual fomenta este controle por meio de um conjunto de fatores, como a barreira física que se forma, os compostos alelopáticos liberados pela palhada, os fatores biológicos, entre muitos outros que, consequentemente, levarão à diminuição do uso de herbicidas (MAULI et al., 2009).

Os atributos físicos do solo dizem respeito à capacidade de absorver e reter água, de circular o ar e à facilidade que oferece para a penetração das raízes das plantas (PENTEADO, 2007). Atributos como a densidade e porosidade total mostram se um solo apresenta condições adequadas para o desenvolvimento e exploração das raízes, indicando se há problemas de compactação (RAMIREZ-LOPEZ et al., 2008).

Estudos realizados por Vieira e Klein (2007) relataram que dos componentes do manejo, o preparo do solo é a atividade que mais influi no seu comportamento físico, pois interfere diretamente na sua estrutura, causando modificações na porosidade e densidade, que afetam a retenção de água e a resistência mecânica, entre outros efeitos.

Conforme De Polli e Pimentel (2005) a matéria orgânica tem papel preponderante na maioria das propriedades físicas, químicas e biológicas do solo. A junção das partículas minerais e orgânicas, de diferentes tamanhos, favorece a formação de agregados, cuja organização melhora a estrutura e a capacidade de armazenamento de água no solo.

A densidade do solo não afeta diretamente o crescimento das plantas ou a erodibilidade do solo. No entanto, em função de seu aumento, ocorrem mudanças em outras propriedades tais como: porosidade, resistência mecânica do solo, aeração e disponibilidade de água (LACEY, 1993). Quanto mais elevada for a densidade do solo, maior será sua compactação, menor sua porosidade total e conseqüentemente, maiores serão as restrições ao desenvolvimento das plantas e dificuldades a serem enfrentadas nas operações de preparo do solo (COSTA et al., 2002).

A porosidade total é descrita como a porcentagem do volume do solo não ocupado por partículas sólidas, incluindo todo o espaço poroso ocupado pelo ar e água (CURI et al., 1993). Esta inclui a macroporosidade e a microporosidade e pode ser calculada pela relação entre as densidades real e do solo. A macroporosidade é definida como o número de poros maiores, no caso aqueles que não são capazes de transportar água por capilaridade, enquanto que a microporosidade se refere aos poros capazes de exercer esta função (KIEHL, 1979).

$\mathrm{O}$ armazenamento, a disponibilidade e o transporte da solução do solo e do ar não só dependem da porosidade total, mas também de como o espaço poroso total é distribuído por tamanho, ou seja, a quantidade de macro e microporos (PREVEDELLO, 1996).

\section{REVENG}

33-45 p. ENGENHARIA NA AGRICULTURA, VIÇOSA - MG, V.20 N.1, JANEIRO / FEVEREIRO 2012 
No solo, a água ocupa os espaços porosos formados do arranjo físico das partículas da fase sólida, competindo e freqüentemente, concorrendo com a fase gasosa do solo. Da água que chega ao solo, uma parte é armazenada; a água do solo é altamente dinâmica, exibindo variação no tempo e no espaço, sobretudo perto da superfície do solo, devido à evaporação e atividade das raízes das plantas. Mudanças no conteúdo de água do solo e no seu estado de energia afetam muito as suas propriedades mecânicas, incluindo resistência, compactabilidade e penetrabilidade, podendo causar mudanças na densidade de solos expansivos (Or e Wraith, 2000 apud GONZÁLEZ; ALVES, 2005).

O volume de macroporos pode ser reduzido pela utilização de matéria orgânica como a fornecida por água residuária de suinocultura, como foi verificado por Pacheco et al. (2009). Contudo, a utilização de plantas de cobertura pode favorecer a diminuição da macroporosidade do solo pelo bom desenvolvimento de seu sistema radicular.

Neste contexto, o objetivo deste trabalho foi avaliar a densidade, teor de água, macro e microporosidade do solo cultivado com soja e milho em sistema de plantio direto e rotação de culturas com milheto, trigo, aveia preta, colza e nabo forrageiro, utilizados como plantas de cobertura de inverno.

\section{MATERIAL E MÉTODOS}

O experimento foi conduzido no NEEA Núcleo Experimental de Engenharia Agrícola da Universidade Estadual do Oeste do Paraná Unioeste, localizado no município de Cascavel, a $24^{\circ} 58^{\prime}$ de latitude Sul e $53^{\circ} 26^{\prime}$ de longitude Oeste de Greenwich, com altitude média de 800 $\mathrm{m}$, clima temperado, mesotérmico e superúmido (KOPPEN), com temperatura anual em torno de $21{ }^{\circ} \mathrm{C}$. A região está sujeita a geadas.

O solo da área experimental é classificado, de acordo com EMBRAPA (1997), como LATOSSOLO Vermelho escuro distroférrico típico, com relevo suavemente ondulado. $\mathrm{O}$ experimento foi realizado sob sistema de plantio direto, no período de dezembro de 2000 a novembro de 2001.

A área foi dividida em 24 parcelas de $5,8 \mathrm{~m}$ de comprimento por $1,8 \mathrm{~m}$ de largura. Dessas, as primeiras 12 parcelas, com quatro linhas de semeadura, foram destinadas à cultura de soja e as outras 12 parcelas restantes, com três linhas de semeadura, para a cultura do milho. Entre as parcelas, foram deixadas bordaduras de $1 \mathrm{~m}$, com quatro repetições para cada tratamento de plantas de cobertura.

As culturas da soja e do milho foram semeadas no mês de dezembro de 2000 e foram colhidas no mês de março de 2001. Após a colheita, os restos culturais permaneceram sobre o solo durante a realização do experimento.

As plantas de cobertura de inverno foram semeadas em abril de 2001, permanecendo até o mês de agosto de 2001, com exceção do milheto, o qual foi semeado em agosto de 2001 e permaneceu até o mês de novembro de 2001.

A determinação do teor de água do solo seguiu a metodologia descrita em EMBRAPA (1997). As amostras foram coletadas aleatoriamente, uma em cada parcela, na profundidade de 0,00 a $0,10 \mathrm{~m}$. Foram realizadas sempre entre os dias 20 e 25 de cada mês, no período de dezembro de 2000 a novembro de 2001, durante os ciclos das culturas do milho e da soja e das coberturas vegetais de inverno.

Em campo, cápsulas de alumínio foram distribuídas nas parcelas e coletadas uma porção de solo. Em laboratório, foram pesadas em balança de precisão $0,001 \mathrm{~g}$ e acondicionadas em estufa a temperatura de $105{ }^{\circ} \mathrm{C} \pm 3{ }^{\circ} \mathrm{C}$, por 24 horas, sendo em seguida resfriadas em dessecador e novamente pesadas. O teor de água foi expresso em porcentagem.

A determinação da densidade do solo foi pelo método do anel volumétrico (EMBRAPA, 1997). Cilindros de metal com 0,05 $\mathrm{m}$ de altura, 0,045 m de diâmetro e massas conhecidas, foram utilizados e amostras de solos indeformadas foram obtidas de 0,00 a $0,10 \mathrm{~m}$ de profundidade.

As mesmas amostras dos cilindros foram utilizadas para determinação da macro e microporosidade do solo por meio da mesa de 
tensão (KIEHL, 1979), sendo que, as 24 amostras receberam uma cobertura no fundo de tecido tipo perfex, os quais foram presos por um atilho de borracha, com intuito de evitar a perda de solo no momento da saturação.

Após o preparo, os anéis foram conduzidos para uma bandeja plástica que continha volume de água equivalente a $2 / 3$ de suas alturas e deixados em repouso por $24 \mathrm{~h}$ até atingir a saturação. Decorrido este período, os anéis foram pesados em balança de precisão $0,001 \mathrm{~g}$ e levados à mesa de tensão, na qual repousaram por 24 horas. Posteriormente, iniciou-se a pesagem em intervalos de 3 horas, até a estabilização da massa dos anéis.

Em seguida, foram retirados o tecido tipo perfex e o atilho de borracha. Então os anéis retornaram à estufa a $105{ }^{\circ} \mathrm{C} \pm 3{ }^{\circ} \mathrm{C}$, por 24 horas, e a seguir foram levados ao dessecador até atingirem temperatura ambiente e pesados novamente. Com os dados obtidos, determinou-se a massa do solo saturada, a massa estabilizada e a massa seca, determinando-se a macroporosidade a partir da massa saturada com a massa estabilizada, enquanto que, a microporosidade foi por meio da massa estabilizada e massa seca. A porosidade total é a soma da macro e microporosidade, expressas em porcentagem.

Esquematizou-se o experimento em delineamento estatístico inteiramente casualizado, em esquema fatorial $2 \times 6$, com duas culturas (soja e milho) $x$ seis coberturas (aveia preta, colza, milheto, nabo forrageiro, trigo e pousio).

As médias das variáveis, respostas densidade, teor de água, macroporosidade e microporosidade foram comparadas pelo teste de Tukey a $5 \%$ de probabilidade, processadas no software ESTAT (UNESP, 1991).

\section{RESULTADOS E DISCUSSÕES}

Observa-se no Quadro 1, no período de dezembro de 2000 a novembro de 2001, diferença estatística entre os teores de água do solo nas áreas de soja e milho, nos meses de janeiro, fevereiro, março e junho de 2001.

Nesses meses, os valores de teor de água apresentaram-se elevados e foram maiores na cultura da soja. No mês de junho, quando havia plantas de cobertura sobre o solo, também foi observada diferença, mas o teor de água mais elevado ocorreu nas áreas em que anteriormente se encontrava a cultura do milho, o que provavelmente deve ter ocorrido em função de maior quantidade de restos culturais sobre o solo, decorrentes da colheita da cultura.

Com a compactação do solo a quantidade de água disponível para as plantas (valores de teor de água superiores a $8 \%$ ) tende a diminuir, devido à deterioração da estrutura do solo, reduzindo, significativamente, a produtividade da cultura (SÁ; Júnior, 2005). No entanto, não houve redução do teor de água do solo ao longo do tempo. Tal comportamento pode ser indicativo de êxito no uso de plantas de cobertura.

A cultura da soja apresentou valores de teor de água entre 15,9 e $26,1 \%$, de modo que, estes resultados foram superiores aos encontrados por Pacheco et al. (2009), que avaliaram o teor de água de um Latossolo Vermelho Distroférrico, em sistema plantio direto, com cobertura morta (palha de milho), durante um ciclo da cultura da soja, obtendo valores entre 12,7 a $24,3 \%$.

Não foram observadas diferenças entre as coberturas, nem nos meses mais secos (dezembro/2000, agosto/2001 e outubro/2001) (SIMEPAR, 2000/2001).

No Quadro 2 são apresentados os resultados de densidade do solo $\left(\mathrm{g} \mathrm{cm}^{-3}\right)$, obtidos nos meses de dezembro de 2000 a novembro de 2001.

Observa-se diferença estatística entre os valores de densidade do solo nas áreas cultivadas com soja e milho nos meses de dezembro de 2000 e março de 2001. Verifica-se que, em dezembro de 2000, a cultura encontrava-se em início de desenvolvimento, podendo o sistema radicular do milho ter melhorado as condições do solo. No mês de março de 2001, havia sobre o solo restos culturais, sendo que o milho propiciou, além de maior quantidade de palha, decomposição mais lenta, podendo-se explicar a menor densidade por este aspecto. 
Quadro 1. Resultados do teor de água do solo (\%) obtidos no período de dezembro de 2000 a novembro de 2001 em Cascavel - PR

\begin{tabular}{|c|c|c|c|c|c|c|c|c|}
\hline Mês & $\begin{array}{c}\text { Cobertura/ } \\
\text { Cultura }\end{array}$ & $\begin{array}{l}\text { Aveia } \\
\text { preta }\end{array}$ & Colza & Milheto & $\begin{array}{c}\text { Nabo } \\
\text { Forrageiro }\end{array}$ & Pousio & Trigo & $\begin{array}{l}\text { Médias } \\
\text { culturas }\end{array}$ \\
\hline & Soja & 20,6 & 19,8 & 20,3 & 19,5 & 18,7 & 18,7 & $19,6 \mathrm{~A}$ \\
\hline Dezembro & Milho & 18,2 & 18,1 & 19,6 & 18,7 & 18,4 & 18,4 & $18,6 \mathrm{~A}$ \\
\hline \multirow[t]{2}{*}{ Médias } & Coberturas & $19,4 \mathrm{a}$ & $19,0 \mathrm{a}$ & $19,9 \mathrm{a}$ & $19,1 \mathrm{a}$ & $18,6 \mathrm{a}$ & $18,5 \mathrm{a}$ & \\
\hline & Soja & 25,0 & 25,4 & 24,7 & 24,1 & 23,8 & 26,3 & $24,9 \mathrm{~A}$ \\
\hline Janeiro & Milho & 23,8 & 23,0 & 24,7 & 21,5 & 24,0 & 22,7 & $23,2 \mathrm{~B}$ \\
\hline \multirow[t]{2}{*}{ Médias } & Coberturas & $24,4 \mathrm{a}$ & $24,2 \mathrm{a}$ & $24,7 \mathrm{a}$ & $22,8 \mathrm{a}$ & $23,9 \mathrm{a}$ & $24,5 \mathrm{a}$ & \\
\hline & Soja & 25,7 & 27,2 & 25,7 & 25,5 & 25,1 & 23,5 & $25,9 \mathrm{~A}$ \\
\hline Fevereiro & Milho & 24,7 & 26,2 & 25,4 & 25,3 & 25,2 & 25,1 & $25,3 \mathrm{~B}$ \\
\hline \multirow[t]{2}{*}{ Médias } & Coberturas & $25,2 \mathrm{a}$ & $26,7 \mathrm{a}$ & $25,5 \mathrm{a}$ & $25,4 \mathrm{a}$ & $25,1 \mathrm{a}$ & $25,8 \mathrm{a}$ & \\
\hline & Soja & 24,3 & 24,9 & 24,8 & 25,2 & 24,0 & 25,2 & $24,7 \mathrm{~A}$ \\
\hline Março & Milho & 23,4 & 24,1 & 24,1 & 22,2 & 25,2 & 23,6 & $23,8 \mathrm{~B}$ \\
\hline \multirow[t]{2}{*}{ Médias } & Coberturas & $23,9 \mathrm{a}$ & $24,5 \mathrm{a}$ & $24,5 \mathrm{a}$ & $23,7 \mathrm{a}$ & $24,6 \mathrm{a}$ & $24,4 \mathrm{a}$ & \\
\hline & Soja & 23,4 & 23,50 & 23,6 & 27,2 & 23,1 & 24,2 & $24,2 \mathrm{~A}$ \\
\hline \multirow{3}{*}{ Médias } & Milho & 23,5 & 24,23 & 24,6 & 23,6 & 23,1 & 21,6 & $23,4 \mathrm{~A}$ \\
\hline & Coberturas & $23,5 \mathrm{a}$ & $23,86 \mathrm{a}$ & $24,1 \mathrm{a}$ & $25,4 \mathrm{a}$ & $23,1 \mathrm{a}$ & $22,9 \mathrm{a}$ & \\
\hline & Soja & 25,1 & 23,9 & 24,9 & 23,4 & 24,3 & 24,3 & $24,3 \mathrm{~A}$ \\
\hline \multirow{2}{*}{$\begin{array}{c}\text { Maio } \\
\text { Médias }\end{array}$} & Milho & 24,7 & 25,5 & 25,5 & 23,9 & 24,9 & 24,7 & $24,8 \mathrm{~A}$ \\
\hline & Coberturas & $24,9 \mathrm{a}$ & $24,7 \mathrm{a}$ & $25,2 \mathrm{a}$ & $23,7 \mathrm{a}$ & $24,6 \mathrm{a}$ & $24,5 \mathrm{a}$ & \\
\hline Médias & Soja & 25,5 & 25,4 & 25,0 & 25,5 & 25,8 & 25,7 & $25,3 \mathrm{~B}$ \\
\hline Junho & Milho & 25,7 & 26,2 & 26,1 & 26,1 & 25,0 & 25,5 & $25,8 \mathrm{~A}$ \\
\hline \multirow[t]{2}{*}{ Médias } & Coberturas & $25,1 \mathrm{a}$ & $25,8 \mathrm{a}$ & $25,6 \mathrm{a}$ & $25,8 \mathrm{a}$ & $25,4 \mathrm{a}$ & $25,6 \mathrm{a}$ & \\
\hline & Soja & 25,0 & 26,0 & 25,3 & 23,9 & 25,8 & 26,2 & $25,4 \mathrm{~A}$ \\
\hline Julho & Milho & 25,7 & 26,0 & 25,4 & 24,4 & 24,9 & 24,4 & $25,1 \mathrm{~A}$ \\
\hline \multirow[t]{2}{*}{ Médias } & Coberturas & $25,3 \mathrm{a}$ & $26,0 \mathrm{a}$ & $25,3 \mathrm{a}$ & $24,2 \mathrm{a}$ & $25,4 \mathrm{a}$ & $25,3 \mathrm{a}$ & \\
\hline & Soja & 17,2 & 18,1 & 17,0 & 18,1 & 18,2 & 18,6 & $17,9 \mathrm{~A}$ \\
\hline Agosto & Milho & 17,6 & 18,5 & 18,6 & 17,0 & 18,4 & 18,7 & $18,1 \mathrm{~A}$ \\
\hline \multirow[t]{2}{*}{ Médias } & Coberturas & $17,4 \mathrm{a}$ & $18,3 \mathrm{a}$ & $17,8 \mathrm{a}$ & $17,6 \mathrm{a}$ & $18,3 \mathrm{a}$ & $18,7 \mathrm{a}$ & \\
\hline & Soja & 25,5 & 26,0 & 25,6 & 27,4 & 26,4 & 25,9 & $26,1 \mathrm{~A}$ \\
\hline Setembro & Milho & 25,5 & 26,1 & 27,1 & 24,6 & 25,1 & 25,2 & $25,6 \mathrm{~A}$ \\
\hline \multirow[t]{2}{*}{ Médias } & Coberturas & $25,6 \mathrm{a}$ & $26,1 \mathrm{a}$ & $26,3 \mathrm{a}$ & $26,0 \mathrm{a}$ & $25,7 \mathrm{a}$ & $25,5 \mathrm{a}$ & \\
\hline & Soja & 14,1 & 16,5 & 15,4 & 17,0 & 15,5 & 16,9 & $15,9 \mathrm{~A}$ \\
\hline Outubro & Milho & 12,3 & 16,2 & 16,8 & 13,6 & 13,2 & 14,7 & $14,5 \mathrm{~A}$ \\
\hline \multirow[t]{2}{*}{ Médias } & Coberturas & $13,2 \mathrm{a}$ & $16,3 \mathrm{a}$ & $16,1 \mathrm{a}$ & $15,3 \mathrm{a}$ & $14,4 \mathrm{a}$ & $15,8 \mathrm{a}$ & \\
\hline & Soja & 21,9 & 23,8 & 22,8 & 21,7 & 22,7 & 23,2 & $22,7 \mathrm{~A}$ \\
\hline Novembro & Milho & 23,4 & 23,2 & 23,7 & 22,1 & 21,3 & 22,6 & $22,7 \mathrm{~A}$ \\
\hline Médias & Coberturas & $22,7 \mathrm{a}$ & $23,5 \mathrm{a}$ & $23,3 \mathrm{a}$ & $21,9 \mathrm{a}$ & $22,0 \mathrm{a}$ & $22,9 \mathrm{a}$ & \\
\hline
\end{tabular}

Médias seguidas da mesma letra minúscula na linha e maiúscula na coluna, não diferem entre si, pelo teste de Tukey, a $5 \%$ de probabilidade. 
Não foram observadas diferenças nos meses em que o solo foi cultivado com as coberturas de inverno, pois os valores apresentaram pouca diferença, causada pela variação do teor de água e não pela presença de restos culturais de plantas de coberturas.

Quadro 2. Resultados de densidade do solo $\left(\mathrm{g} \mathrm{cm}^{-3}\right)$ obtidos nos meses de dezembro de 2000 a novembro de 2001 em Cascavel - PR

\begin{tabular}{|c|c|c|c|c|c|c|c|c|}
\hline Mês & $\begin{array}{c}\text { Cobertura/ } \\
\text { Cultura }\end{array}$ & $\begin{array}{l}\text { Aveia } \\
\text { preta }\end{array}$ & Colza & Milheto & $\begin{array}{c}\text { Nabo } \\
\text { forrageiro }\end{array}$ & Pousio & Trigo & $\begin{array}{l}\text { Médias } \\
\text { culturas }\end{array}$ \\
\hline & Soja & 1,39 & 1,33 & 1,33 & 1,33 & 1,34 & 1,40 & $1,35 \mathrm{~A}$ \\
\hline Dezembro & Milho & 1,28 & 1,30 & 1,19 & 1,36 & 1,13 & 1,39 & $1,27 \mathrm{~B}$ \\
\hline \multirow[t]{2}{*}{ Médias } & Coberturas & $1,33 \mathrm{a}$ & $1,31 \mathrm{a}$ & $1,26 \mathrm{a}$ & $1,34 \mathrm{a}$ & $1,23 \mathrm{a}$ & $1,40 \mathrm{a}$ & \\
\hline & Soja & 1,40 & 1,37 & 1,34 & 1,26 & 1,35 & 1,44 & $1,36 \mathrm{~A}$ \\
\hline Janeiro & Milho & 1,31 & 1,32 & 1,31 & 1,29 & 1,31 & 1,39 & $1,32 \mathrm{~A}$ \\
\hline \multirow[t]{2}{*}{ Médias } & Coberturas & $1,36 \mathrm{a}$ & $1,35 \mathrm{a}$ & $1,33 \mathrm{a}$ & $1,28 \mathrm{a}$ & $1,33 \mathrm{a}$ & $1,42 \mathrm{a}$ & \\
\hline & Soja & 1,37 & 1,32 & 1,41 & 1,28 & 1,34 & 1,39 & $1,35 \mathrm{~A}$ \\
\hline Fevereiro & Milho & 1,34 & 1,32 & 1,35 & 1,26 & 1,23 & 1,29 & $1,30 \mathrm{~A}$ \\
\hline \multirow[t]{2}{*}{ Médias } & Coberturas & $1,35 \mathrm{a}$ & $1,32 \mathrm{a}$ & $1,38 \mathrm{a}$ & $1,27 \mathrm{a}$ & $1,27 \mathrm{a}$ & $1,34 \mathrm{a}$ & \\
\hline & Soja & 1,38 & 1,35 & 1,40 & 1,37 & 1,31 & 1,31 & $1,35 \mathrm{~A}$ \\
\hline Março & Milho & 1,37 & 1,30 & 1,20 & 1,23 & 1,32 & 1,25 & $1,28 \mathrm{~B}$ \\
\hline \multirow[t]{2}{*}{ Médias } & Coberturas & $1,38 \mathrm{a}$ & $1,33 \mathrm{a}$ & $1,30 \mathrm{a}$ & $1,30 \mathrm{a}$ & $1,31 \mathrm{a}$ & $1,28 \mathrm{a}$ & \\
\hline & Soja & 1,33 & 1,36 & 1,32 & 1,33 & 1,31 & 1,36 & $1,33 \mathrm{~A}$ \\
\hline & Milho & 1,29 & 1,31 & 1,35 & 1,27 & 1,36 & 1,45 & $1,34 \mathrm{~A}$ \\
\hline \multirow[t]{2}{*}{ Médias } & Coberturas & $1,31 \mathrm{a}$ & $1,34 \mathrm{a}$ & $1,33 \mathrm{a}$ & $1,30 \mathrm{a}$ & $1,33 \mathrm{a}$ & $1,40 \mathrm{a}$ & \\
\hline & Soja & 1,45 & 1,37 & 1,35 & 1,37 & 1,29 & 1,45 & $1,37 \mathrm{~A}$ \\
\hline Maio & Milho & 1,32 & 1,36 & 1,36 & 1,32 & 1,37 & 1,39 & $1,35 \mathrm{~A}$ \\
\hline \multirow{2}{*}{ Médias } & Coberturas & $1,39 \mathrm{a}$ & $1,36 \mathrm{a}$ & $1,35 \mathrm{a}$ & $1,35 \mathrm{a}$ & $1,33 \mathrm{a}$ & $1,42 \mathrm{a}$ & \\
\hline & Soja & 1,34 & 1,41 & 1,31 & 1,23 & 1,30 & 1,37 & $1,32 \mathrm{~A}$ \\
\hline & Milho & 1,35 & 1,31 & 1,34 & 1,36 & 1,21 & 1,33 & $1,31 \mathrm{~A}$ \\
\hline \multirow{2}{*}{ Médias } & Coberturas & $1,34 \mathrm{a}$ & $1,36 \mathrm{a}$ & $1,32 \mathrm{a}$ & $1,29 \mathrm{a}$ & $1,25 \mathrm{a}$ & $1,35 \mathrm{a}$ & \\
\hline & Soja & 1,25 & 1,24 & 1,26 & 1,28 & 1,30 & 1,34 & $1,27 \mathrm{~A}$ \\
\hline \multirow{3}{*}{$\begin{array}{c}\text { Julho } \\
\text { Médias } \\
\end{array}$} & Milho & 1,30 & 1,27 & 1,31 & 1,20 & 1,28 & 1,31 & $1,28 \mathrm{~A}$ \\
\hline & Coberturas & $1,27 \mathrm{a}$ & $1,25 \mathrm{a}$ & $1,28 \mathrm{a}$ & $1,24 \mathrm{a}$ & $1,28 \mathrm{a}$ & $1,32 \mathrm{a}$ & \\
\hline & Soja & 1,33 & 1,35 & 1,38 & 1,23 & 1,30 & 1,35 & $1,32 \mathrm{~A}$ \\
\hline \multirow{3}{*}{$\begin{array}{l}\text { Agosto } \\
\text { Médias } \\
\end{array}$} & Milho & 1,41 & 1,36 & 1,29 & 1,33 & 1,33 & 1,30 & $1,33 \mathrm{~A}$ \\
\hline & Coberturas & $1,37 \mathrm{a}$ & $1,35 \mathrm{a}$ & $1,33 \mathrm{a}$ & $1,28 \mathrm{a}$ & $1,31 \mathrm{a}$ & $1,32 \mathrm{a}$ & \\
\hline & Soja & 1,31 & 1,29 & 1,29 & 1,21 & 1,30 & 1,29 & $1,28 \mathrm{~A}$ \\
\hline \multirow{2}{*}{$\frac{\text { Setembro }}{\text { Médias }}$} & Milho & 1,36 & 1,30 & 1,31 & 1,22 & 1,27 & 1,30 & $1,29 \mathrm{~A}$ \\
\hline & Coberturas & $1,33 \mathrm{a}$ & $1,30 \mathrm{a}$ & $1,30 \mathrm{a}$ & $1,21 \mathrm{a}$ & $1,28 \mathrm{a}$ & $1,29 \mathrm{a}$ & \\
\hline \multirow[b]{2}{*}{ Outubro } & Soja & 1,23 & 1,29 & 1,18 & 1,27 & 1,12 & 1,23 & $1,22 \mathrm{~A}$ \\
\hline & Milho & 1,08 & 1,13 & 1,20 & 1,15 & 1,18 & 1,24 & $1,16 \mathrm{~A}$ \\
\hline \multirow[t]{2}{*}{ Médias } & Coberturas & $1,16 \mathrm{a}$ & $1,21 \mathrm{a}$ & $1,19 \mathrm{a}$ & $1,21 \mathrm{a}$ & $1,15 \mathrm{a}$ & $1,23 \mathrm{a}$ & \\
\hline & Soja & 1,32 & 1,36 & 1,28 & 1,31 & 1,35 & 1,40 & $1,33 \mathrm{~A}$ \\
\hline \multirow{2}{*}{$\frac{\text { Novembro }}{\text { Médias }}$} & Milho & 1,33 & 1,31 & 1,28 & 1,23 & 1,30 & 1,29 & $1,29 \mathrm{~A}$ \\
\hline & Coberturas & $1,32 \mathrm{a}$ & $1,33 \mathrm{a}$ & $1,28 \mathrm{a}$ & $1,27 \mathrm{a}$ & $1,33 \mathrm{a}$ & $1,34 \mathrm{a}$ & \\
\hline
\end{tabular}

Médias seguidas da mesma letra minúscula na linha e maiúscula na coluna, não diferem entre si, pelo teste de Tukey, a $5 \%$ de probabilidade. 
Como a densidade está relacionada com o teor de água no solo, com a precipitação elevada do mês de dezembro de 2000 e a temperatura média diária elevada, a média de teor de água no solo foi muito alta, porém não interferiu na densidade do solo. Em março de 2001, o teor de água diferiu entre as culturas, sendo que a cultura da soja apresentou a densidade mais elevada.

Os valores de densidade obtidos estão abaixo do sugerido por Donahue (1965), citado por Fernandes (1993), que determinou $1,4 \mathrm{~g} \mathrm{~cm}^{-3}$ como o valor máximo de densidade para solos argilosos, ou seja, valor acima do qual as condições de aeração e penetração de raízes ficam prejudicadas. Para o solo estudado, Prior (1999) encontrou densidade máxima de $1,44 \mathrm{~g} \mathrm{~cm}^{-3}$. Segundo Buckman e Brady (1967), os sistemas de cultivo e o manejo do solo influenciam na densidade, especialmente nas camadas superficiais, quando há aplicação de resíduos orgânicos em grandes quantidades, tendendo a diminuir os valores, da mesma forma que o cultivo de gramíneas. Foi observado decréscimo dos valores de densidade em função dos cultivos, como verificado pelos autores citados. Conforme Denardin (1999), o manejo de solo convencional contribui para a degradação da estrutura do solo, expressa pelo decréscimo da porosidade, permeabilidade, estabilidade de agregados e aumento da compactação.

Resultados de macroporosidade do solo (\%) obtidos nos meses de março de 2001 a novembro de 2001 são apresentados no Quadro 3.

Ao longo do período, pode-se verificar acréscimo nos valores de macroporosidade nos meses estudados, o que mostra efeito positivo de todas as coberturas sobre o solo.

Observa-se diferença estatística entre os valores de macroporosidade do solo nas áreas de soja e milho nos meses de maio e outubro de 2001, sendo que os valores médios mais elevados foram observados na cultura do milho. Nos demais meses não houve diferença significativa. No mês de março de 2001 os valores médios de macroporosidade diferiram, significativamente entre si, sendo maior a macroporosidade na área destinada à cobertura de trigo, a qual diferiu apenas da aveia. Para as demais coberturas, não foram encontradas diferenças. Essa determinação foi realizada no final do ciclo das culturas de milho e soja. Nos demais meses não houve diferença para o parâmetro cobertura.

Apesar das observações terem ocorrido apenas ao longo de um ano, foi constatada diferença favorável da macroporosidade inicial, com média de aproximadamente $4 \%$ no mês de março de 2001 , observando-se a média de aproximadamente $15 \%$ no mês de novembro de 2001, com aumento gradual ao longo dos meses. Isso contraria os resultados obtidos por Kettler et al. (2000) que constataram que o solo, após o manejo de plantas invasoras no sistema plantio direto, não sofreu alteração em sua estrutura próximo à superfície. Neste trabalho notou-se que, com o passar dos meses, a macroporosidade aumentou, favorecendo o solo como afirmou Magalhães (1990).

Pacheco et al. (2009) realizaram estudos em solo irrigado com água residuária, cultivado com soja e concluíram que ocorreu diminuição da macroporosidade. Isto pode ser explicado pelo fato de que a cultura da soja não supriu a diminuição da macroporosidade causada pelo uso de água residuária. É possível que, no presente trabalho, a cultura do milho auxiliou no aumento da macroporosidade do solo, já que a soja não foi eficiente.

Solos em quais a macro e microporosidade estão distribuídas satisfatoriamente, a drenagem é muito favorecida. Ao contrário, se o solo estiver saturado, o número de macroporos está abaixo do exigido para a ideal condutibilidade hidráulica e, consequentemente, bom desenvolvimento radicular. Com o aumento da macroporosidade do solo esperava-se a diminuição da densidade do solo, pois, segundo Moraes e Tamburús (1993), o aumento da macroporosidade tende a favorecer a diminuição da densidade e da compactação do solo, uma vez que este último parâmetro está diretamente ligado à densidade do solo. Portanto, contrariando esta afirmação, a densidade permaneceu constante, mesmo com o aumento significativo da macroporosidade. Este comportamento pode ter se manifestado devido ao fato do solo já apresentar valores para densidade dentro do aceitável (Quadro 2), ou seja, abaixo de 1,4 $\mathrm{g} \mathrm{cm}^{-3}$ para solos argilosos. Este fenômeno também foi verificado por outros autores, citados por Dias Junior e Pierce (1996), que concluíram que a compactação do solo aumenta a densidade e a sua resistência mecânica à penetração, diminuindo a porosidade total. 
À medida que os valores da macroporosidade aumentaram, a microporosidade foi reduzida quase que na mesma proporção, fazendo com que os valores da porosidade total do solo permanecessem constantes. Os dados obtidos mostraram que a cobertura vegetal contribuiu para o aumento da macroporosidade, favorecendo o desenvolvimento das plantas e a melhoria das condições do solo.

No Quadro 4 são apresentados os resultados de microporosidade do solo (\%) obtidos nos meses de março de 2001 a novembro de 2001.

Observa-se em todos os meses, que não houve diferença estatística entre os valores de microporosidade, porém, verificou-se que, apesar do curto período do experimento, houve diminuição dos valores no decorrer dos meses. Isto ocorreu em razão do aumento da macroporosidade, já que existe relação direta entre ambas. Estes resultados vão de encontro aos observados por Kettler et al. (2000), que afirmaram que um solo sob plantio direto e plantas invasoras não tem afetado nem a estrutura nem sua densidade próximo à superfície. Este solo, por sua vez, modificou a relação entre macro e microporosidade, vindo a diminuir esta última no tempo de desenvolvimento do experimento, sendo que o solo era cultivado sob plantio direto há mais de cinco anos.

Quadro 3. Resultados de macroporosidade do solo (\%) obtidos no período de março de 2001 a novembro de 2001 em Cascavel - PR

\begin{tabular}{|c|c|c|c|c|c|c|c|c|}
\hline Mês & $\begin{array}{c}\text { Cobertura/ } \\
\text { Cultura }\end{array}$ & $\begin{array}{l}\text { Aveia } \\
\text { preta }\end{array}$ & Colza & Milheto & $\begin{array}{c}\text { Nabo } \\
\text { forrageiro }\end{array}$ & Pousio & Trigo & $\begin{array}{l}\text { Médias } \\
\text { culturas }\end{array}$ \\
\hline & Soja & 3,81 & 5,06 & 3,71 & 4,86 & 3,96 & 4,85 & $4,37 \mathrm{~A}$ \\
\hline Março & Milho & 2,72 & 3,23 & 4,36 & 4,01 & 3,64 & 5,44 & $3,90 \mathrm{~A}$ \\
\hline \multirow[t]{2}{*}{ Médias } & Coberturas & $3,27 \mathrm{~b}$ & $4,14 \mathrm{ab}$ & $4,04 \mathrm{ab}$ & $4,44 \mathrm{ab}$ & $3,80 \mathrm{ab}$ & $5,15 \mathrm{a}$ & \\
\hline & Soja & 7,35 & 8,54 & 6,76 & 6,47 & 7,82 & 7,82 & $7,46 \mathrm{~A}$ \\
\hline Abril & Milho & 7,08 & 7,45 & 8,12 & 7,68 & 6,16 & 6,71 & $7,20 \mathrm{~A}$ \\
\hline \multirow[t]{2}{*}{ Médias } & Coberturas & $7,21 \mathrm{a}$ & $7,99 \mathrm{a}$ & $7,44 \mathrm{a}$ & $7,07 \mathrm{a}$ & $6,99 \mathrm{a}$ & $7,26 \mathrm{a}$ & \\
\hline & Soja & 9,72 & 10,32 & 9,34 & 9,23 & 5,96 & 9,05 & $8,93 \mathrm{~B}$ \\
\hline Maio & Milho & 9,61 & 9,75 & 13,67 & 12,46 & 9,14 & 12,46 & $11,18 \mathrm{~A}$ \\
\hline \multirow[t]{2}{*}{ Médias } & Coberturas & $9,66 \mathrm{a}$ & $10,04 \mathrm{a}$ & $11,50 \mathrm{a}$ & $10,85 \mathrm{a}$ & $7,55 \mathrm{a}$ & $10,75 \mathrm{a}$ & \\
\hline & Soja & 10,92 & 9,78 & 11,78 & 14,32 & 11,17 & 9,96 & $11,32 \mathrm{~A}$ \\
\hline Junho & Milho & 10,75 & 12,04 & 9,81 & 11,58 & 17,00 & 10,08 & $11,88 \mathrm{~A}$ \\
\hline \multirow[t]{2}{*}{ Médias } & Coberturas & $10,84 \mathrm{a}$ & $10,91 \mathrm{a}$ & $10,80 \mathrm{a}$ & $12,95 \mathrm{a}$ & $14,08 \mathrm{a}$ & $10,02 \mathrm{a}$ & \\
\hline & Soja & 13,94 & 17,40 & 15,12 & 15,61 & 13,32 & 14,18 & $14,93 \mathrm{~A}$ \\
\hline Julho & Milho & 17,38 & 14,73 & 15,33 & 20,20 & 15,26 & 14,15 & $16,17 \mathrm{~A}$ \\
\hline \multirow[t]{2}{*}{ Médias } & Coberturas & $15,66 \mathrm{a}$ & $16,06 \mathrm{a}$ & $15,22 \mathrm{a}$ & $17,90 \mathrm{a}$ & $14,29 \mathrm{a}$ & $14,17 \mathrm{a}$ & \\
\hline & Soja & 13,14 & 10,73 & 9,43 & 13,92 & 14,29 & 9,92 & $11,90 \mathrm{~A}$ \\
\hline Agosto & Milho & 10,35 & 13,06 & 14,06 & 14,50 & 11,29 & 13,96 & $12,87 \mathrm{~A}$ \\
\hline \multirow[t]{2}{*}{ Médias } & Coberturas & $11,75 \mathrm{a}$ & $11,89 \mathrm{a}$ & $11,74 \mathrm{a}$ & $14,21 \mathrm{a}$ & $12,79 \mathrm{a}$ & $11,94 \mathrm{a}$ & \\
\hline & Soja & 11,21 & 11,70 & 9,66 & 11,68 & 9,30 & 13,01 & $11,09 \mathrm{~A}$ \\
\hline Setembro & Milho & 9,90 & 11,52 & 10,89 & 14,25 & 13,18 & 10,49 & $11,70 \mathrm{~A}$ \\
\hline \multirow[t]{2}{*}{ Médias } & Coberturas & $10,56 \mathrm{a}$ & $11,61 \mathrm{a}$ & $10,27 \mathrm{a}$ & $12,96 \mathrm{a}$ & $11,24 \mathrm{a}$ & $11,75 \mathrm{a}$ & \\
\hline & Soja & 15,53 & 11,70 & 15,45 & 12,29 & 18,18 & 14,94 & $14,68 \mathrm{~B}$ \\
\hline \multirow{3}{*}{$\begin{array}{c}\text { Outubro } \\
\text { Médias } \\
\end{array}$} & Milho & 22,61 & 17,83 & 19,02 & 20,48 & 18,93 & 13,89 & $18,79 \mathrm{~A}$ \\
\hline & Coberturas & $19,07 \mathrm{a}$ & $14,76 \mathrm{a}$ & $17,24 \mathrm{a}$ & $16,38 \mathrm{a}$ & $18,55 \mathrm{a}$ & $14,41 \mathrm{a}$ & \\
\hline & Soja & 14,64 & 11,85 & 15,68 & 14,22 & 11,85 & 11,20 & $13,24 \mathrm{~A}$ \\
\hline Novembro & Milho & 14,96 & 16,64 & 16,86 & 18,65 & 9,09 & 15,95 & $15,36 \mathrm{~A}$ \\
\hline Médias & Coberturas & $14,80 \mathrm{a}$ & $14,24 \mathrm{a}$ & $16,27 \mathrm{a}$ & $16,43 \mathrm{a}$ & $10,47 \mathrm{a}$ & $13,58 \mathrm{a}$ & \\
\hline
\end{tabular}

Médias seguidas da mesma letra minúscula na linha e maiúscula na coluna, não diferem entre si, pelo teste de Tukey, a 5\% de significância. 
Quadro 4. Resultados de microporosidade do solo (\%) obtidos no período de março de 2001 a novembro de 2001 em Cascavel - PR

\begin{tabular}{|c|c|c|c|c|c|c|c|c|}
\hline Mês & $\begin{array}{c}\text { Cobertura/ } \\
\text { Cultura }\end{array}$ & $\begin{array}{l}\text { Aveia } \\
\text { preta }\end{array}$ & Colza & Milheto & $\begin{array}{c}\text { Nabo } \\
\text { forrageiro }\end{array}$ & Pousio & Trigo & $\begin{array}{l}\text { Médias } \\
\text { culturas }\end{array}$ \\
\hline & Soja & 52,91 & 52,39 & 53,32 & 53,72 & 52,90 & 53,55 & $53,13 \mathrm{~A}$ \\
\hline Março & Milho & 51,73 & 54,29 & 53,81 & 52,34 & 52,51 & 51,79 & $52,74 \mathrm{~A}$ \\
\hline \multirow[t]{2}{*}{ Médias } & coberturas & $52,32 \mathrm{a}$ & $53,34 \mathrm{a}$ & $53,56 \mathrm{a}$ & $53,03 \mathrm{a}$ & $52,71 \mathrm{a}$ & $52,67 \mathrm{a}$ & \\
\hline & Soja & 49,63 & 51,88 & 51,82 & 49,76 & 51,59 & 52,58 & $51,21 \mathrm{~A}$ \\
\hline Abril & Milho & 50,28 & 52,35 & 46,79 & 46,90 & 52,24 & 52,89 & $50,24 \mathrm{~A}$ \\
\hline \multirow[t]{2}{*}{ Médias } & coberturas & $49,96 \mathrm{a}$ & $52,11 \mathrm{a}$ & $49,30 \mathrm{a}$ & $48,33 \mathrm{a}$ & $51,91 \mathrm{a}$ & $52,74 \mathrm{a}$ & \\
\hline & Soja & 43,70 & 44,90 & 44,36 & 43,71 & 43,61 & 44,77 & $44,17 \mathrm{~A}$ \\
\hline Maio & Milho & 43,81 & 45,67 & 44,04 & 42,16 & 43,87 & 43,14 & $43,78 \mathrm{~A}$ \\
\hline \multirow[t]{2}{*}{ Médias } & coberturas & $43,75 \mathrm{a}$ & $45,28 \mathrm{a}$ & $44,20 \mathrm{a}$ & $42,94 \mathrm{a}$ & $43,74 \mathrm{a}$ & $43,96 \mathrm{a}$ & \\
\hline & Soja & 45,75 & 45,55 & 44,40 & 42,33 & 40,87 & 45,36 & $44,04 \mathrm{~A}$ \\
\hline Junho & Milho & 44,32 & 45,68 & 45,41 & 45,14 & 39,57 & 44,49 & $44,10 \mathrm{~A}$ \\
\hline \multirow[t]{2}{*}{ Médias } & coberturas & $45,04 \mathrm{a}$ & $45,62 \mathrm{a}$ & $44,90 \mathrm{a}$ & $43,73 \mathrm{a}$ & $40,22 \mathrm{a}$ & $44,92 \mathrm{a}$ & \\
\hline & Soja & 41,75 & 40,34 & 40,85 & 42,73 & 43,88 & 42,95 & $42,08 \mathrm{~A}$ \\
\hline Julho & Milho & 41,78 & 37,02 & 42,64 & 33,66 & 36,00 & 42,07 & $38,86 \mathrm{~A}$ \\
\hline \multirow[t]{2}{*}{ Médias } & coberturas & $41,76 \mathrm{a}$ & $38,68 \mathrm{a}$ & $41,74 \mathrm{a}$ & 38,19 a & $39,94 \mathrm{a}$ & $42,51 \mathrm{a}$ & \\
\hline & Soja & 45,69 & 46,81 & 47,19 & 45,02 & 44,92 & 46,64 & $46,04 \mathrm{~A}$ \\
\hline Agosto & Milho & 45,93 & 45,59 & 43,01 & 45,70 & 45,05 & 43,48 & $44,49 \mathrm{~A}$ \\
\hline \multirow[t]{2}{*}{ Médias } & coberturas & $45,81 \mathrm{a}$ & $46,20 \mathrm{a}$ & $45,10 \mathrm{a}$ & $45,36 \mathrm{a}$ & $44,98 \mathrm{a}$ & $45,06 \mathrm{a}$ & \\
\hline & Soja & 45,39 & 29,35 & 45,96 & 37,03 & 39,79 & 37,86 & $39,23 \mathrm{~A}$ \\
\hline Setembro & Milho & 55,92 & 41,50 & 41,82 & 44,61 & 37,09 & 47,71 & $44,77 \mathrm{~A}$ \\
\hline \multirow[t]{2}{*}{ Médias } & coberturas & $50,66 \mathrm{a}$ & $35,42 \mathrm{a}$ & $43,89 \mathrm{a}$ & $40,82 \mathrm{a}$ & $38,44 \mathrm{a}$ & $42,79 \mathrm{a}$ & \\
\hline & Soja & 48,52 & 48,88 & 46,02 & 49,02 & 42,70 & 46,53 & $46,94 \mathrm{~A}$ \\
\hline Outubro & Milho & 41,45 & 44,56 & 45,16 & 45,08 & 45,15 & 46,23 & $44,27 \mathrm{~A}$ \\
\hline \multirow[t]{2}{*}{ Médias } & coberturas & $45,00 \mathrm{a}$ & $46,72 \mathrm{a}$ & $45,58 \mathrm{a}$ & $46,05 \mathrm{a}$ & $43,92 \mathrm{a}$ & $46,38 \mathrm{a}$ & \\
\hline & Soja & 46,13 & 48,69 & 46,78 & 46,26 & 48,86 & 48,23 & $47,49 \mathrm{~A}$ \\
\hline Novembro & Milho & 45,46 & 44,85 & 44,16 & 43,20 & 51,34 & 44,73 & $45,62 \mathrm{~A}$ \\
\hline Médias & coberturas & $45,80 \mathrm{a}$ & $46,77 \mathrm{a}$ & $45,47 \mathrm{a}$ & $44,73 \mathrm{a}$ & $50,10 \mathrm{a}$ & $46,48 \mathrm{a}$ & \\
\hline
\end{tabular}

Médias seguidas da mesma letra minúscula na linha e maiúscula na coluna, não diferem entre si, pelo teste de Tukey, a 5\% de significância.

Este resultado contraria Moraes e Tamburús (1993), os quais observaram em um Latossolo Bruno, aumento de $26,92 \%$ para $49,78 \%$ na microporosidade, diminuição na macroporosidade de $41,72 \%$ para $2,55 \%$ e redução da porosidade total de $68,64 \%$ para $52,33 \%$. Já no solo do experimento, a microporosidade média do solo diminuiu de $52,94 \%$ para $45,56 \%$. Este resultado é contrário ao observado por Pacheco et al. (2009), em que a microporosidade aumentou de 35,81\% para $49,62 \%$, a macroporosidade diminuiu de $64,18 \%$ para $50,38 \%$, em relação à porosidade total. Mesmo com a redução da microporosidade, a densidade permaneceu com seus valores médios, sem variação.

No Quadro 5 são apresentados os resultados da porosidade do solo (\%), para o período de março de 2001 a novembro de 2001. 
Quadro 5. Resultados de porosidade do solo (\%), para o período de março de 2001 a novembro de 2001, em Cascavel - PR

\begin{tabular}{|c|c|c|c|c|c|c|c|c|}
\hline Mês & $\begin{array}{c}\text { Cobertura/ } \\
\text { Cultura }\end{array}$ & $\begin{array}{l}\text { Aveia } \\
\text { preta }\end{array}$ & Colza & Milheto & $\begin{array}{c}\text { Nabo } \\
\text { forrageiro }\end{array}$ & Pousio & Trigo & $\begin{array}{l}\text { Médias } \\
\text { culturas }\end{array}$ \\
\hline & Soja & 56,72 & 57,40 & 57,03 & 58,58 & 56,86 & 58,40 & $57,40 \mathrm{~A}$ \\
\hline Março & Milho & 54,45 & 57,51 & 58,17 & 57,85 & 56,15 & 57,23 & $56,89 \mathrm{~A}$ \\
\hline \multirow[t]{2}{*}{ Médias } & coberturas & $55,59 \mathrm{a}$ & $57,46 \mathrm{a}$ & $57,60 \mathrm{a}$ & $57,21 \mathrm{a}$ & $56,50 \mathrm{a}$ & $57,81 \mathrm{a}$ & \\
\hline & Soja & 56,98 & 60,41 & 58,58 & 56,23 & 59,40 & 60,40 & $58,66 \mathrm{~A}$ \\
\hline Abril & Milho & 57,36 & 59,80 & 54,90 & 54,57 & 58,39 & 59,60 & $57,43 \mathrm{~A}$ \\
\hline \multirow[t]{2}{*}{ Médias } & coberturas & $57,17 \mathrm{a}$ & $60,10 \mathrm{a}$ & $56,74 \mathrm{a}$ & $55,40 \mathrm{a}$ & $58,90 \mathrm{a}$ & $60,00 \mathrm{a}$ & \\
\hline & Soja & 53,42 & 53,71 & 53,70 & 52,94 & 49,56 & 53,82 & $52,86 \mathrm{~B}$ \\
\hline Maio & Milho & 53,42 & 55,41 & 57,71 & 54,62 & 53,01 & 55,60 & $54,96 \mathrm{~A}$ \\
\hline \multirow[t]{2}{*}{ Médias } & coberturas & $53,42 \mathrm{a}$ & $54,56 \mathrm{a}$ & $55,70 \mathrm{a}$ & $53,78 \mathrm{a}$ & $51,29 \mathrm{a}$ & $54,71 \mathrm{a}$ & \\
\hline & Soja & 56,67 & 55,33 & 56,18 & 56,64 & 52,23 & 55,31 & $55,39 \mathrm{~A}$ \\
\hline Junho & Milho & 55,08 & 57,73 & 55,22 & 56,71 & 56,58 & 54,57 & $55,98 \mathrm{~A}$ \\
\hline \multirow[t]{2}{*}{ Médias } & coberturas & $55,87 \mathrm{a}$ & $56,53 \mathrm{a}$ & $55,69 \mathrm{a}$ & $56,68 \mathrm{a}$ & $54,40 \mathrm{a}$ & $54,94 \mathrm{a}$ & \\
\hline & Soja & 55,68 & 57,74 & 55,95 & 58,34 & 57,20 & 57,13 & $57,00 \mathrm{~A}$ \\
\hline Julho & Milho & 59,16 & 56,74 & 57,97 & 53,86 & 51,26 & 56,22 & $55,87 \mathrm{~A}$ \\
\hline \multirow[t]{2}{*}{ Médias } & coberturas & $57,42 \mathrm{a}$ & $57,24 \mathrm{a}$ & $56,96 \mathrm{a}$ & $56,10 \mathrm{a}$ & $54,23 \mathrm{a}$ & $56,67 \mathrm{a}$ & \\
\hline & Soja & 58,83 & 57,54 & 56,61 & 59,34 & 59,21 & 56,56 & $58,01 \mathrm{~A}$ \\
\hline Agosto & Milho & 56,28 & 58,59 & 57,07 & 60,21 & 56,33 & 57,44 & $57,65 \mathrm{~A}$ \\
\hline \multirow[t]{2}{*}{ Médias } & coberturas & $57,55 \mathrm{a}$ & $58,07 \mathrm{a}$ & $56,84 \mathrm{a}$ & $59,77 \mathrm{a}$ & $57,77 \mathrm{a}$ & $57,00 \mathrm{a}$ & \\
\hline & Soja & 56,60 & 41,05 & 55,61 & 48,71 & 49,08 & 50,87 & $50,32 \mathrm{~A}$ \\
\hline \multirow{3}{*}{ Médias } & Milho & 69,56 & 53,02 & 52,71 & 58,87 & 50,27 & 58,20 & $57,10 \mathrm{~A}$ \\
\hline & coberturas & $63,08 \mathrm{a}$ & $47,03 \mathrm{a}$ & $54,16 \mathrm{a}$ & $53,79 \mathrm{a}$ & $49,67 \mathrm{a}$ & $54,53 \mathrm{a}$ & \\
\hline & Soja & 56,60 & 41,05 & 55,61 & 48,71 & 49,08 & 50,87 & $50,32 \mathrm{~A}$ \\
\hline \multirow{2}{*}{$\frac{\text { Outubro }}{\text { Médias }}$} & Milho & 69,56 & 53,02 & 52,71 & 58,87 & 50,27 & 58,20 & $57,10 \mathrm{~A}$ \\
\hline & coberturas & $63,08 \mathrm{a}$ & $47,03 \mathrm{a}$ & $54,16 \mathrm{a}$ & $53,79 \mathrm{a}$ & $49,67 \mathrm{a}$ & $54,53 \mathrm{a}$ & \\
\hline Médias & Soja & 64,06 & 60,58 & 61,47 & 61,30 & 60,86 & 61,46 & $61,62 \mathrm{~A}$ \\
\hline Novembro & Milho & 64,06 & 62,39 & 64,18 & 63,56 & 64,07 & 60,12 & $63,06 \mathrm{~A}$ \\
\hline Médias & coberturas & $64,06 \mathrm{a}$ & $61,48 \mathrm{a}$ & $62,82 \mathrm{a}$ & $62,43 \mathrm{a}$ & $62,46 \mathrm{a}$ & $60,79 \mathrm{a}$ & \\
\hline
\end{tabular}

Médias seguidas da mesma letra minúscula na linha e maiúscula na coluna, não diferem entre si, pelo teste de Tukey, a 5\% de significância.

Observa-se diferença estatística entre os valores de porosidade do solo, nas áreas de soja e milho, no mês de maio. Os dados de teor de água e densidade, no mês de maio, não apresentaram diferenças estatísticas, não afetando, assim, a porosidade. Nos demais meses não se observou diferença significativa.

Apesar de ter sido verificado diferença significativa na macroporosidade, para a porosidade total não se verificou diferença entre as médias, porque ocorreu juntamente com o aumento da macroporosidade e diminuição da microporosidade, concordando com Albuquerque et al. (1995), que verificaram que a rotação de culturas e os sistemas de manejo do solo amenizam estes problemas e atuam na reestruturação do solo. A condição estrutural pode ser analisada avaliandose os parâmetros relacionados com a porosidade do solo. Como o solo teve sua porosidade aumentada, pode-se concluir que apresente melhor estruturação. 
A rotação de culturas pode ser considerada uma forma de minimizar o problema da baixa aeração dos solos, uma vez que, quanto maior a porosidade, maior a aeração, destacando a preocupação de Urquiaga et al. (2005), que ressaltaram a importância de se obter um solo bem aerado, evitando a compactação. Com a rotação de culturas, a porosidade tende a aumentar, apesar do pouco tempo de implantação. Isso também foi verificado por Voorhees e Lindstrom (1984), os quais afirmaram que são necessários três a quatro anos para que um solo, sob condições de manejo conservacionista, desenvolva porosidade mais favorável na camada de $0-15 \mathrm{~cm}$. Isto pode explicar o comportamento deste solo, caso este aumento mantenha-se ao longo de três anos. Fazendo a rotação e com cobertura de inverno, o solo terá sua porosidade distribuída de maneira satisfatória, com a relação entre macro e microporosidade.

\section{CONCLUSÕES}

- A cultura do milho apresentou-se mais eficiente para aumento da macroporosidade do solo se comparada à cultura da soja;

- A cobertura vegetal nabo forrageiro contribuiu na melhoria da macroporosidade do solo, contudo, as coberturas vegetais de inverno não influenciaram os valores de teor de água, densidade, microporosidade e porosidade;

- As plantas de cobertura de inverno, apesar de não influenciarem a física do solo, podem ser recomendadas por fatores benéficos que elas proporcionam para o desenvolvimento de outras culturas; e

- A cultura do milho pode ser recomendada para melhoria da estrutura do solo para sistema de plantio direto, em prazo mais curto, pois com o sistema radicular desenvolvido atuando durante o ciclo da cultura, aliado a quantidade de palha gerada após a colheita e a rotação de culturas, melhora a estrutura do solo pela adição de matéria orgânica e substâncias cimentantes, podendo auxiliar, ainda, na estabilidade dos agregados.

\section{REFERÊNCIAS BIBLIOGRÁFICAS}

ALBUQUERQUE, A.S.; SOUZA, C.M.; FIGUEIREDO, M.S. Influência da compressão, textura e umidade na compactação do solo. In: XXIV Congresso Brasileiro de Engenharia Agrícola, 1995, Viçosa, MG. Anais do XXIV Congresso Brasileiro de Engenharia agrícola, v. 1. p. 353-353, jul. 1995.

BUCKMAN, H.O. ; BRADY, N.C. Natureza e propriedade dos solos. 7.ed. Tradução de A. B. DE FIGUEIREDO FILHO. Rio de Janeiro: Freitas Bastos, 1989. 594p.

CALEGARI, A. Plantas de cobertura. In: CASÃO JUNIOR, R.; SIQUEIRA, R.; MEHTA, Y. R.; PASSINI, J.J. Plantio direto com qualidade. Londrina: IAPAR; 2006, v.1, cap. 5. Foz do Iguaçu: ITAIPU Binacional, 2006, p.55-73.

COSTA, L.M.; COSTA, O.V.; OLSZEVSKI, N.; NACIF, P.G.S. Influência das características morfológicas, estruturais e texturais do solo na definição de seu preparo. In: GONÇALVES, J.L.M.; STAPE, J.L. Conservação e cultivo de solos para plantações florestais. Piracicaba: IPEF, 2002. v.1, cap.4, p.205-219.

CURI, N.; LARACH, J.O.I.; KÄMPF, N.; MONIZ, A.C.; FONTES, L.E.F. Vocabulário de ciência do solo. Campinas: Sociedade Brasileira de Ciência do solo. 1993. p.90.

DE-POLLI, H.; PIMENTEL, M. S. Indicadores de qualidade do solo. In: AQUINO, A. M.; ASSIS, R. L. (eds.) Processos biológicos no sistema solo-planta: ferramentas para uma agricultura sustentável. Brasília-DF: Embrapa Informação Tecnológica; Seropédica: Embrapa Agrobiologia, 2005. v.1, cap. 1. p. 17-28.

DENARDIN, J. E. Projeto metas: uma parceria em pesquisa e desenvolvimento aplicada ao sistema plantio direto no Sul do Brasil. In: RASOLO, F.; RAUNET, M., (Ed.). Gestion agrobiologique des sols et des systems de culture. Montpellier: CIRAD, 1999. v.1, cap.4, p. 419-428. 
EMBRAPA- Centro Nacional de Pesquisa de Solos. Manual e métodos de análise de solo - $2^{\circ}$ ed. Rio de Janeiro, 1997. 212p. (Documentos).

FERNANDES, M.R. Alterações na estrutura de Latossolos argilosos submetidos ao uso agrícola. 141f. Dissertação (Mestrado em Engenharia - Água e Solo), Universidade de Campinas, Campinas, 1993.

GONZÁLES, A.P.; ALVES, M.C. Armazenamento de água e densidade do solo sob três condições de superfície, em um Cambissol gleico de Lugo, Espanha. Revista Brasileira de Engenharia Agrícola e Ambiental, Campina Grande, v.9, n.1, p.45-50, jun. 2005.

KADIOGLU, I.; YANAR, Y.; ASAV, U. Allelopathic effects of weeds extracts against seed germination of some plants. Journal of Environmental Biology, Vikas Nagar, v. 26, n. 2, p. 169-173, april, 2005.

KETTLER, T.A. ; LYON, D.J. ; DORAN, J.W. ; POWERS, W.L. ; STROUP, W.W. et al. Soil quality assessment after weed-control tillage in a no-till wheat-fallow cropping system. Soil Science Society America Journal, Madison, v.64, p.339346, jan-fev, 2000.

KIEHL, E.J. Manual de edafologia: relações soloplanta. 2ed. São Paulo: Ceres, 1979. p. 76-215.

LACEY, S.T. Soil deformation and erosion in forestry. $1^{\circ}$ edição. Sydney: Forestry Commission of New South Wales. 1993. 62p.

MAGALHÃES, P.S.G. Manejo de solo e seus efeitos sobre a compactação. Lavoura Arrozeira, Porto Alegre, v. 43, n. 392, p. 14-17, set/out, 1990.

MAULI, M.M.; NÓBREGA, L.H.P.; ROSA, D.M.; LIMA, G.P.; SANTORUM, M.; PACHECO, F.P. Variação da quantidade de resíduos de culturas de inverno usadas como cobertura vegetal sobre a incidência de plantas invasoras. In: $\mathrm{X}$ Congresso Argentino de Ingeniería Rural y II del MERCOSUR, 2009, Rosario - Santa Fé. Actas... Rosario: CADIR, 2009. p. 929 - 935. CD Rom.
MORAES, M.H.; TAMBURÚS, C.E. Influência da compactação na densidade, porosidade, retenção de água e condutibilidade hidráulica de dois solos argilosos. In: CONGRESSO BRASILEIRO DE ENGENHARIA AGRÍCOLA, XXII, 1993, Ilhéus. Anais... Ilhéus BA: Sociedade Brasileira de Engenharia Agrícola, 1993. p. 2234-2248.

PACHECO, F.P.; TONINI M., NÓBREGA, L.H.P.; SANTORUM, M.; DAL BOSCO, T.D. SAMPAIO, S.C. Monitoramento das propriedades físicas do solo irrigado com água residuária no cultivo da soja. In: LEO, N.D.; MONTICO, S.; NARDÓN, G. Avances em ingeniería rural 2007-2009. $1^{\circ}$ edição. Rosario: UNR Editora, Rosário - Santa Fé -Argentina. 2009, p. 796-803.

PENTEADO, S.R. Adubação verde e produção de biomassa: melhoria e recuperação dos solos. $1^{\circ}$ edição. Campinas - SP: Fraga \& Penteado. Livros Via Orgânica, 2007, 164 p.

PREVEDELLO, C.L. Física do solo com problemas resolvidos. $1^{\mathrm{o}}$ edição. Curitiba: Discovery, 1996. 446p.

PRIOR, M. Caracterização física do solo na cultura da soja, sob dois sistemas de cultivo. 1999. 49 f. Trabalho de conclusão de curso Engenharia Agrícola - UNIOESTE, Cascavel, 1999.

RAMIREZ-LOPEZ，L;; REINA-SANCHEZ，A.E CAMACHO-TAMAYO, J.H. Variabilidad espacial de atributos físicos de un Typic Haplustox de los Llanos Orientales de Colômbia. Engenharia Agrícola, Jaboticabal, v.28, n.1, p. 55-63, marzo, 2008.

SÁ, M.A.C. de; SANTOS JUNIOR, J.D.G. Compactação do solo: consequências para o crescimento vegetal. Planaltina - DF, 2005. 26 p. Documentos EMBRAPA Cerrados n 136.

ROSA, D.M.; NÓBREGA, L.H.P.; LIMA, G.P.; MAULI, M.M.; TONINI M.; PACHECO, F.P. Cultura do milho implantada sobre resíduos culturais de leguminosas de verão em sistema plantio direto. In: LEO, N.D.; MONTICO, S.; NARDÓN, G. Avances em ingeniería rural 
2007-2009. Rosário - Santa Fé - Argentina: UNR Editora. 2009, p. 415-421.

SIMEPAR, Tecnologia e informações ambientais 2000/2001 Região de Cascavel. Disponível em: <http://www.simepar.br>.Acesso em: 17/11/2010.

THEISEN, G.; VIDAL, R.A.; FLECK, N.G. Redução da infestação de Brachiaria plantaginea em soja pela cobertura do solo com palha de aveia preta. Pesquisa Agropecuária Brasileira, Brasília, v. 35, n.04, abril, p.753-756, 2000.

URQUIAGA, S.; JANTALIA, C.P.; ZOTARELLI, L.; ALVES, B.J.R.; BODDEY, R.M. Manejo de sistemas agrícolas para seqüestro de carbono no solo. In: AQUINO, A.M.; ASSIS, R.L. Processos biológicos no sistema solo-planta: ferramentas para uma agricultura sustentável. $1^{\circ}$ edição. Brasília, DF: Embrapa Informação Tecnológica,
2005, p. 323-342.

VIDAL, R.A.; TREZZI, M.M. Potencial da utilização de coberturas vegetais de sorgo e milheto na supressão de plantas daninhas em condição de campo: I - plantas em desenvolvimento vegetativo. Planta Daninha, Viçosa, v. 22, n. 2, p. 217-233, abril/junho, 2004.

VIEIRA, M.L. ; KLEIN, V. A. Propriedades físicohídricas de um Latossolo Vermelho submetido a diferentes sistemas de manejo. Revista Brasileira de Ciência do Solo, Viçosa, v.31, n.6, p. 12711280, dezembro, 2007.

VOORHEES, W.B.; LINDSTROM, M.J. Long term effects of tillage method on soil tilth independent of wheel traffic compaction. Soil Science Society America Journal, Madison, v.48, p.152-156, January-February, 1984. 